\title{
SUSTENTABILIDADE NA REGIÃO METROPOLITANA DO CARIRI - RMC: ANÁLISE A PAR- TIR DOS OBJETIVOS DE DESENVOLVIMENTO DO MILÊNIO - ODMS
}

\author{
Sustainability in the Cariri metropolitan region: analysis from the millennium \\ development goals - MDGs
}

Diego Coelho do Nascimento Universidade Federal de Pernambuco - UFPE, Recife, Pernambuco, Brasil. diego.coelho@ufca.edu.br

Suely Salgueiro Chacon Universidade Federal do Ceará - UFC, Fortaleza, Ceará, Brasil. suelychacon@gmail.com

Artigo recebido em 05/09/2015 e aceito para publicação em 18/11/2016

RESUMO: A Região Metropolitana do Cariri - RMC criada pela Lei Complementar No 78 de 2009, localiza-se ao Sul do estado do Ceará no Nordeste brasileiro e é constituída pelos municípios de Juazeiro do Norte, Crato, Barbalha, Jardim, Missão Velha, Caririaçu, Farias Brito, Nova Olinda e Santana do Cariri. A região atravessa uma acentuada fase de crescimento econômico e demográfico, e, consequentemente, de mudanças sociais e ambientais. O objetivo geral dessa pesquisa foi o de identificar o panorama da Região Metropolitana do Cariri no que diz respeito às dimensões componentes do desenvolvimento sustentável a partir da análise dos Objetivos de Desenvolvimento do Milênio na esfera municipal. A pesquisa possui foco quali-quantitativo, constituindo-se em um Estudo de Caso realizado por meio de pesquisa bibliográfica e documental. A coleta de dados se realizou por meio da análise dos Objetivos de Desenvolvimento do Milênio no âmbito dos municípios da RMC. Por meio da análise dos resultados, notou-se que a prosperidade econômica nessa região (sobretudo, no CRAJUBAR) contrasta com a vulnerabilidade social e ambiental, produzindo um ambiente insustentável a médio e longo prazo.

Palavras-chave: Desenvolvimento Regional Sustentável; Políticas Públicas; Território; Qualidade de vida.

ABSTRACT: The Cariri Metropolitan Region-CMR created by the complementary law No. 78 from 2009, It's located in the southern region of Ceará, in northeastern Brazil it is formed by these municipalities: Juazeiro do Norte, Crato, Barbalha, Jardim, Missão Velha, Caririaçu, Farias Brito, Nova Olinda and Santana do Cariri. The region is experiencing a great phase of economic and demographic growth and consequently, social and environmental changes. This research's main goal was identifying the panorama of the Cariri Metropolitan Region with regard to the components dimensions of sustainable development from the analysis of the Millennium Development Goals at the local level. The research has qualitative and quantitative focus, it is constituted in a Case Study conducted through bibliographical and documentary research. Data gathering was conducted through the analysis of the Millennium development goals within the framework of the CMR municipalities. By the analysis results, it's been noticed that economic prosperity in this region (especially in Crajubar - Crato, Juazeiro do Norte and Barbalha) diverges with the social and environmental vulnerability, creating an unsustainable environment in medium and long term.

Keywords: Sustainable Regional Development; Public Policy; Territory; Life Quality. 
Sustentabilidade na região metropolitana do Cariri-RMC: análise a partir dos objetivos de desenvolvimento do milênio - ODMs Diego Coelho do Nascimento, Suely Salgueiro Chacon

\section{INTRODUÇÃO}

O presente estudo reflete sobre o desenvolvimento sustentável da Região Metropolitana do Cariri - RMC em suas dimensões ambiental, social e econômica, por meio da análise das metas municipais dos Objetivos de Desenvolvimento do Milênio - ODMs.

A Região Metropolitana do Cariri foi criada em 2009, localizada na região sul do estado com posição geográfica privilegiada no centro do nordeste brasileiro. Essa região metropolitana é, atualmente, composta por nove municípios: Juazeiro do Norte, Crato, Barbalha, Jardim, Missão Velha, Caririaçu, Farias Brito, Nova Olinda e Santana do Cariri e foi idealizada a partir da relação de conurbação previamente existente entre suas três principais cidades: Juazeiro do Norte, Crato e Barbalha que formam o aglomerado urbano denominado de CRAJUBAR. A RM do Cariri concentra uma população de 564.478 habitantes em uma área total de $5456,012 \mathrm{Km}^{2}$ (IBGE, 2010).

A Região Metropolitana - RM foi idealizada pelo governo estadual visando a criação de um novo polo de desenvolvimento socioeconômico que pudesse dividir com a Região Metropolitana de Fortaleza a atração de investimentos e ampliar a qualidade de vida de sua população. O Cariri se constituiu enquanto região metropolitana em virtude de ser a segunda região urbana mais expressiva do estado, muito devido a conurbação formada pelos municípios de Crato, Juazeiro do Norte e Barbalha, denominada de Triângulo CRAJUBAR.

$\mathrm{O}$ atual conjunto de municípios que integram a Região Metropolitana do Cariri possui elevado potencial de crescimento econômico, confirmado pelos investimentos públicos e, sobretudo, privados executados na última década ou em processo de execução nesse território. Os municípios que compõem o Triângulo CRAJUBAR (Crato, Juazeiro do Norte e Barbalha) são os detentores da expressão econômica regional e configuram-se em centros secundários no interior do Estado do Ceará, concentrando a maior parte do contingente populacional e detendo os melhores indicadores socioeconômicos regionais.

A realização da pesquisa partiu do seguinte questionamento: Qual o panorama atual da Região Metropolitana do Cariri no que diz respeito às dimensões da sustentabilidade?
O termo Sustentabilidade ou Desenvolvimento Sustentável foram usados pela primeira vez quando da publicação do Relatório Brundlant - Nosso Futuro Comum da Comissão Mundial sobre Meio Ambiente e Desenvolvimento da Organização das Nações Unidas ONU. O Desenvolvimento Sustentável é compreendido como "aquele que atende às necessidades atuais sem comprometer a capacidade das futuras gerações em satisfazer suas próprias necessidades" (WCED, 1987).

O Desenvolvimento Sustentável adveio da necessidade de mudança no modelo de "desenvolvimento" da sociedade atual pautado na esfera econômica com grandes e, muitas vezes, irreversíveis impactos sobre o meio natural. Ao se referir ao ambiente urbano, pode-se considerar a perspectiva do Desenvolvimento Sustentável urbano como forma de combate aos problemas existentes nesse espaço.

Derivou-se como hipótese a esse questionamento norteador que a Região Metropolitana do Cariri não contempla no seu estágio atual de crescimento às dimensões da sustentabilidade, tampouco possui planejamento estratégico para isso, haja vista a centralização de estratégias na dimensão econômica com o consequente agravamento de problemas ambientais e sociais.

O objetivo geral desse trabalho identificar o panorama da Região Metropolitana do Cariri no que diz respeito às dimensões componentes do desenvolvimento sustentável. Nesse estudo, foram analisados os indicadores municipais dos Objetivos de Desenvolvimento do Milênio de cada um dos municípios da RMC a fim de obter um panorama das dimensões da sustentabilidade.

\section{CONSIDERAÇÕES METODOLÓGICAS}

Concernente à classificação, quanto à natureza dos dados a pesquisa em foco teve caráter quali-quantitativo. A junção de aspectos da pesquisa qualitativa e quantitativa é cada vez mais comum, oferecendo aos pesquisadores uma possibilidade de abordagem mais ampla e que contemple, da melhor forma possível, os objetivos elencados nas pesquisas desenvolvidas.

Com relação aos objetivos das pesquisas em gerais, os estudos são classificados em: exploratórios, descritivos ou explicativos. O estudo em foco se enquadrou na proposta exploratória, definidas como aquelas que "têm como propósito proporcionar maior 
familiaridade com o problema, com vistas a torná-lo mais explícito ou a construir hipóteses" (GIL, 2010, p. 27).

Por fim, as pesquisas científicas também são classificadas de acordo com o delineamento utilizado no seu desenvolvimento. Essa pesquisa usou como delineamentos:

1. Pesquisa Bibliográfica: elaborada a partir de materiais já publicados, tais como: materiais impressos (livros, revistas, teses, dissertações, dicionários, enciclopédias, anuários, almanaques e etc), além de outros formatos de informações como discos, fitas magnéticas, CDs e materiais publicados na internet. (GIL, 2010; SEVERINO, 2007).
2. Pesquisa Documental: "Vale-se de toda sorte de documentos, elaborados com finalidades diversas, tais como assentamentos, autorização, comunicação [...] relatos de pesquisa, relatórios e boletins de jornais de empresas, atos jurídicos, compilações estatísticas etc." (GIL, 2010, p. 29).

3. Estudo de Caso: O estudo de caso é o delineamento mais adequado quando se trata de fenômenos contemporâneos, visando à obtenção de maiores esclarecimentos da relação fenômeno/contexto (YIN, 2005).

O estudo se desenvolveu na Região Metropolitana do Cariri, localizada na região sul do estado com posição geográfica privilegiada no centro do nordeste brasileiro (Figura 01).

Figura 01 - Localização da Região Metropolitana do Cariri - RMC

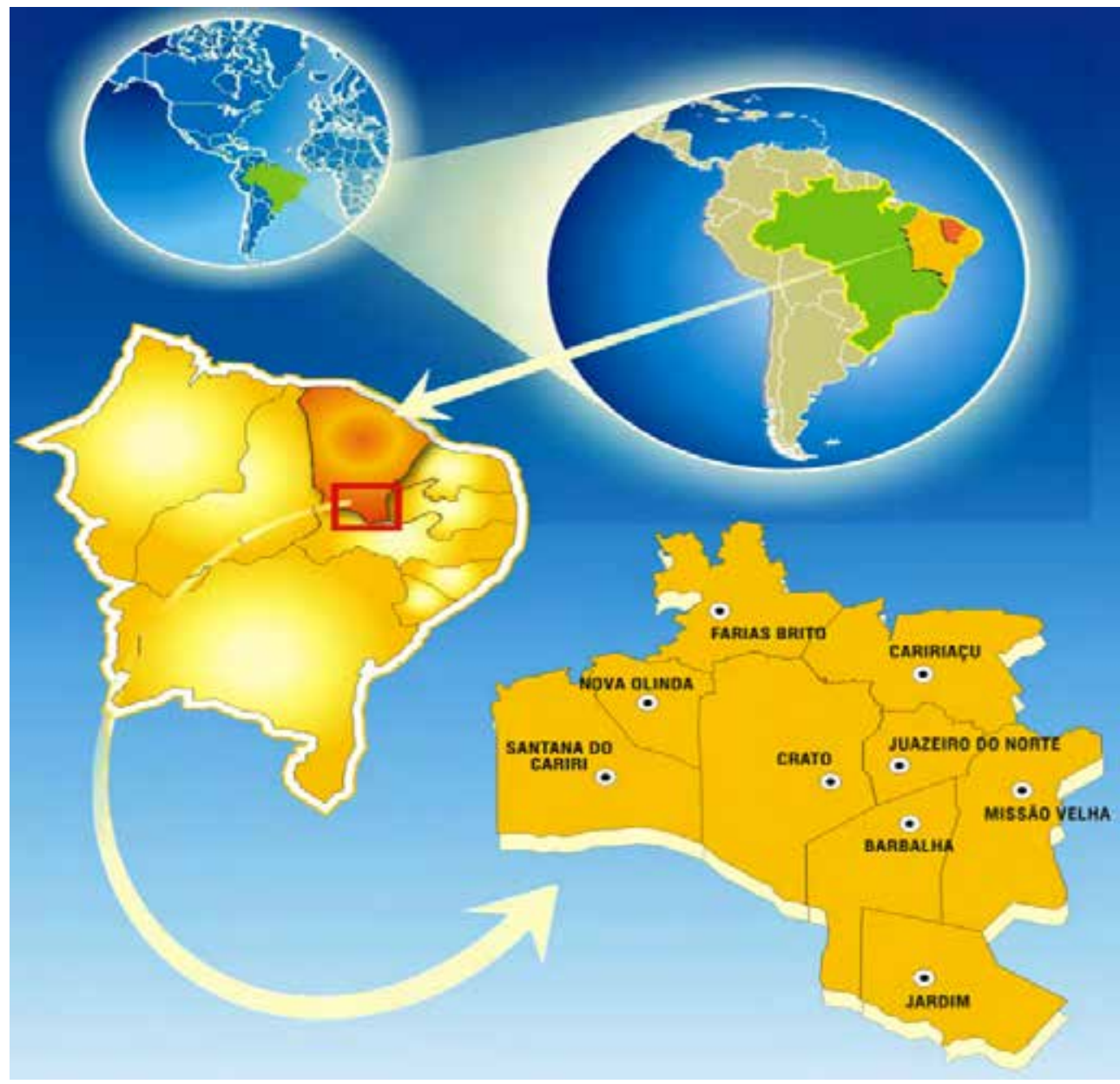

Fonte: Instituto de Pesquisa e Estratégia Econômica do Ceará - IPECE 
A coleta de dados foi realizada entre os meses de março e dezembro de 2012. A avaliação do panorama da Região Metropolitana do Cariri foi realizada por meio da análise das Metas e Objetivos de Desenvolvimento do Milênio. A escolha desse instrumento de coleta de dados se deu pela abrangência da maior quantidade possível de dimensões da sustentabilidade propiciadas pelos mesmos. De acordo com Chacon (2007), o Desenvolvimento Sustentável é composto pelas dimensões: econômica, sociocultural, ambiental e política-institucional.

\section{OS OBJETIVOS DE DESENVOLVIMENTO DO MILÊNIO-ODM'S: UMACONTEXTUALIZAÇÃO NA REGIÃO METROPOLITANA DO CARIRI}

No ano 2000, a Organização das Nações Unidas - ONU durante a Cúpula do Milênio em Nova Iorque (EUA), divulgou um documento intitulado Declaração do Milênio contendo diretrizes denominadas de Objetivos de Desenvolvimento do Milênio - ODM, definidos como "um conjunto de oito diretrizes estabelecidas por países membros da Organização das Nações Unidas (ONU), com o propósito de contribuir para a construção de um mundo pacifico, justo e sustentável no século XXI." (GUIA PARA MUNICIPALIZAÇÃO..., 2009, p. 1).

Os ODMs foram criados após sucessivos debates entre chefes de estado, especialistas e sociedade civil durante as conferências internacionais da ONU na década de 1990. "A ideia desses lideres era descrever o que era necessário fazer para reduzir a pobreza e alcançar o desenvolvimento sustentável ate 2015." (GUIA PARA MUNICIPALIZAÇÃO..., 2009, p. 1).

O Brasil, signatário da Declaração do Milênio, comprometeu-se no mesmo ano de lançamento em cumprir até o ano de 2015 em alcançar os objetivos e metas estipulados nos ODM e, consequentemente, ampliar o desenvolvimento nacional. Dessa maneira, o governo federal em parceria com o Programa das Nações Unidas pelo Desenvolvimento - PNUD e organizações civis e produtivas se mobilizaram em prol do alcance dos ODM e criaram em 2004 a Campanha "Nos Podemos - 8 Jeitos de Mudar o Mundo". Essa campanha de promoção das Metas do Milênio idealizou oito ícones, um para cada ODM, que se tornaram referência a nível nacional e internacional a partir da adoção dessas ilustrações pela ONU como símbolos oficiais dos Objetivos de Desenvolvimento do Milênio (GUIA PARA MUNICIPALIZAÇÃO..., 2009, p. 1).

Os oito jeitos de mudar o mundo na forma dos "Objetivos de Desenvolvimento do Milênio" são: 1. Erradicar a extrema pobreza e a fome; 2. Atingir o ensino básico universal; 3 . Promover a igualdade entre os sexos e a autonomia das mulheres; 4 . Reduzir a mortalidade infantil; 5. Melhorar a saúde materna; 6 . Combater o HIV/aids, a malária e outras doenças; 7. Garantir a sustentabilidade ambiental; 8. Estabelecer uma parceria mundial para o desenvolvimento.

Os ODM's por meio dos seus objetivos, metas e variáveis são importantes ferramentas de análise no que concerne a oferta de diretrizes para a melhoria do desenvolvimento em determinada região, uma vez que, engloba as dimensões econômica, social e ambiental do desenvolvimento sustentável.

\section{Objetivos de Desenvolvimento do Milênio nos Mu- nicípios da RMC}

Nos municípios integrantes da Região Metropolitana do Cariri são grandes as dificuldades de conseguir dados específicos a nível municipal. Entretanto, essa dificuldade já era prevista, visto que "estudos sobre qualidade ambiental e desenvolvimento encontram o desafio frequente de lidar com a incerteza e a carência de informações sistematizadas”. Dessa maneira, pela necessidade "de criar indicadores confiáveis que possam embasar estudos e tomadas de decisão política são cruciais e urgentes (BRAGA et al., 2003, p. 6)."

A análise dos ODMs foi realizada como forma de verificar a realidade das dimensões da sustentabilidade (econômica, social e ambiental) nos municípios da RMC. Além disso, o levantamento dos indicadores relativos aos ODM visou a verificação da existência de disparidades intrarregionais no âmbito de RMC, bem como, a identificação da realidade municipal concernente a cada uma das metas, fazendo correlação com o cenário de crescimento econômico vigente na região.

Os dados secundários relacionados aos Objetivos de Desenvolvimento do Milênio da Região Metropolitana do Cariri foram levantados a partir do acesso aos relatórios dinâmicos municipais dispo- 
níveis no Portal ODM (www.portalodm.com.br). O referido portal é um canal virtual desenvolvido pelo Programa das Nações Unidas para o Desenvolvimento - PNUD e foi lançado em 2009 para permitir o monitoramento da situação dos objetivos e metas do milênio nos 5.565 municípios brasileiros (GUIA PARA MUNICIPALIZAÇÃO..., 2009).

No presente estudo, o oitavo Objetivo de Desenvolvimento do Milênio não será analisado em virtude do mesmo não poder ser adaptado para mensuração na esfera municipal.

\section{ODM 1 - Erradicar a Extrema Pobreza e a Fome}

O primeiro dos oito ODM's, trata-se de acabar com a fome e a miséria. Para isso, a meta proposta foi reduzir pela metade a proporção da população com renda inferior a um dólar por dia. Na mensuração do alcance desse objetivo a nível municipal foram estipulados como indicadores: a proporção de pessoas com renda familiar per capita inferior a meio salário mínimo; intensidade da pobreza - aumento percentual sobre o rendimento médio das pessoas vivendo abaixo da linha da pobreza necessário para transpor essa situação; e participação do quinto mais pobre da população na renda total do município.

Para a Região Metropolitana do Cariri-RMC, os dados referentes ao ODM 1 estão expostos na Tabela 01 , demonstrando as dificuldades para o alcance desse objetivo e as diferenças nos comparativos entre municípios que deveriam integrar uma mesma unidade socioeconômica.

Tabela 01 - Indicadores relativos ao ODM 1

\begin{tabular}{|c|c|c|c|c|}
\hline Município & $\begin{array}{c}\text { Proporção de } \\
\text { pessoas abai- } \\
\text { xo da linha da } \\
\text { pobreza }\end{array}$ & $\begin{array}{c}\text { Redução da proporção de } \\
\text { pessoas com renda domici- } \\
\text { liar per capita inferior a R\$ } \\
140,00 \text { no período de 2000 } \\
\text { a 2010 (\%) }\end{array}$ & $\begin{array}{c}\text { Proporção de pessoas } \\
\text { vivendo abaixo da linha } \\
\text { da pobreza para cum- } \\
\text { prir a meta de 50\% de } \\
\text { redução em 2015 (\%) }\end{array}$ & $\begin{array}{c}\text { Participação do } \\
\text { quinto mais pobre } \\
\text { da população na } \\
\text { renda total do } \\
\text { município - 2000 }\end{array}$ \\
\hline Barbalha & $28,8 \%$ & $50,9 \%$ & $0,0 \%$ & $2,2 \%$ \\
\hline Caririaçu & $45,6 \%$ & $36,0 \%$ & $35,5 \%$ & $1,5 \%$ \\
\hline Crato & $25,2 \%$ & $48,4 \%$ & $24,5 \%$ & $1,6 \%$ \\
\hline Farias Brito & $49,7 \%$ & $25,5 \%$ & $33,3 \%$ & $1,6 \%$ \\
\hline Jardim & $45,8 \%$ & $35,6 \%$ & $35,6 \%$ & $0,0 \%$ \\
\hline Juaz.do Norte & $24,3 \%$ & $48,9 \%$ & $23,7 \%$ & $2,4 \%$ \\
\hline Missão Velha & $44,9 \%$ & $31,6 \%$ & $32,8 \%$ & $1,4 \%$ \\
\hline Nova Olinda & $47,0 \%$ & $25,0 \%$ & $31,3 \%$ & $0,7 \%$ \\
\hline Sant.do Cariri & $56,3 \%$ & $24,3 \%$ & $37,2 \%$ & $0,0 \%$ \\
\hline
\end{tabular}

Fonte: Elaboração Própria a partir de dados obtidos via Portal ODM

No indicador relacionado à proporção de pessoas vivendo abaixo da linha da pobreza (onde estão incluídos indivíduos com renda domiciliar per capita inferior a $\mathrm{R} \$$ 140,00 e, no caso, da indigência, inferior a R\$ 70,00), a maior parte dos municípios da RMC apresenta proporção de pobres superior aos $40 \%$. A única exceção é o Triângulo CRAJUBAR com taxas inferiores à $30 \%$. O destaque positivo fica para Juazeiro do Norte, com a menor proporção de pessoas vivendo com renda per capita abaixo de $\mathrm{R} \$ 140,00$, correspondendo a $24,3 \%$. Já o destaque negativo é Santana do Cariri com mais de
$50 \%$ da população vivendo abaixo da linha da pobreza e é seguida de perto por Farias Brito com quase $50 \%$ da população na mesma condição.

Os segundos e terceiros indicadores estão intimamente relacionados. $\mathrm{O}$ segundo refere-se à redução da proporção de pessoas com renda per capita inferior a $\mathrm{R} \$ 140,00$ e o terceiro diz respeito a que percentual de pessoas vivendo abaixo da linha da pobreza se deve chegar para cumprir a meta de redução de 50\% até 2015 . Nesse cenário, o município de Barbalha se sobressai em virtude de antes mesmo do período estipulado conseguir 
Sustentabilidade na região metropolitana do Cariri-RMC: análise a partir dos objetivos de desenvolvimento do milênio - ODMs Diego Coelho do Nascimento, Suely Salgueiro Chacon

reduzir a proporção da população abaixo da linha da pobreza em mais de 50\%. Logo após, vem, respectivamente, os municípios de Juazeiro do Norte e Crato com uma redução acima dos $48 \%$, faltando pouco mais de $1 \%$ para o alcance da meta estipulada.

Na contramão dos municípios do CRAJUBAR estão em sequência as cidades de Santana do Cariri, Nova Olinda e Farias Brito com reduções inferiores aos 26\% $\mathrm{e}$, consequentemente, exigindo grandes esforços para o alcance da meta e melhoria da qualidade de vida da população. Para efeito comparativo, o estado do Ceará conseguiu reduzir a proporção de pessoas vivendo abaixo da linha da pobreza de 52,3\% em 2000 para 31,6\% em 2010. Dessa maneira, somente os municípios do CRAJUBAR e Missão Velha obtiveram índices iguais ou melhores que os cearenses (PORTAL ODM, 2012).

Por fim, a última variável mensurou a participação do quinto mais pobre da população na renda total do município no ano 2000 (O Portal ODM não disponibilizou dados mais recentes.). A análise desse indicador na Região Metropolitana do Cariri mostrou uma forte concentração de renda em todos os municípios com índices entorno dos $2,5 \%$, demonstrando um quadro crítico de exclusão social. A situação menos crítica no tocante a concentração de renda é a de Juazeiro do Norte, onde os $20 \%$ mais pobres são responsáveis por $2,4 \%$ da renda total do município. As situações mais agravantes são verificadas nos mu- nicípios de Jardim e Santana do Cariri onde o quinto da população mais pobre não responde sequer a $0,1 \%$ da renda total desses municípios.

\section{ODM 2 - Atingir o Ensino Básico Universal}

O segundo ODM se refere a um dos objetivos básicos para qualquer sociedade: a universalização da educação básica. Na análise do mesmo, considera-se a proporção de crianças na faixa etária de 06 a 14 anos que frequentam o Ensino Fundamental; a taxa de conclusão do Ensino Fundamental entre crianças de 15 a 17 anos e a taxa de alfabetização de jovens e adolescentes na faixa etária dos 15 aos 24 anos.

Por meio da análise dos dados da tabela 02 , verifica-se que a proporção de crianças na faixa etária de 06 a 14 anos é relativamente boa, porém, nenhum dos nove municípios sequer chegou ao patamar de $95 \%$ de frequência dessas crianças. Os municípios que mais se aproximaram foram Barbalha e Caririaçu com índices pouco maiores a $93 \%$. Na outra margem, Farias Brito, Missão Velha e Nova Olinda foram, respectivamente, os que obtiveram os piores índices (abaixo de 90\%). De acordo com o Portal ODM (2012), no Ceará a taxa de frequência líquida no ensino fundamental em 2010 era de $89,2 \%$. Sendo assim, os municípios da RMC (a exceção de Farias Brito e Nova Olinda) possuem índices iguais ou superiores a média estadual daquele ano.

Tabela 02 - Indicadores relativos ao ODM 2

\begin{tabular}{|c|c|c|c|}
\hline Município & $\begin{array}{c}\text { Proporção de crianças na faixa } \\
\text { etária de 6 a 14 anos frequen- } \\
\text { tando o Ensino Fundamental - } \\
\mathbf{2 0 1 0}\end{array}$ & $\begin{array}{c}\text { Taxa de conclusão do } \\
\text { Ensino Fundamental } \\
\text { entre crianças de 15 a } \\
\mathbf{1 7} \text { anos - 2010 }\end{array}$ & $\begin{array}{c}\text { Taxa de alfabetização } \\
\text { de jovens e adolescentes } \\
\text { entre 15 e 24 anos - 2010 }\end{array}$ \\
\hline Barbalha & $93,3 \%$ & $57,8 \%$ & $96,7 \%$ \\
\hline Caririaçu & $93,2 \%$ & $43,6 \%$ & $93,5 \%$ \\
\hline Crato & $91,1 \%$ & $59,6 \%$ & $97,0 \%$ \\
\hline Farias Brito & $85,9 \%$ & $69,7 \%$ & $95,6 \%$ \\
\hline Jardim & $90,5 \%$ & $51,0 \%$ & $95,8 \%$ \\
\hline Juazeiro do Norte & $91,6 \%$ & $56,8 \%$ & $96,5 \%$ \\
\hline Missão Velha & $89,2 \%$ & $58,4 \%$ & $93,8 \%$ \\
\hline Nova Olinda & $89,3 \%$ & $47,1 \%$ & $95,1 \%$ \\
\hline Santana do Cariri & $92,0 \%$ & $55,6 \%$ & $94,1 \%$ \\
\hline
\end{tabular}

Fonte: Elaboração Própria a partir de dados obtidos via Portal ODM 
Quando se trata da taxa de conclusão do Ensino Fundamental entre crianças de 15 a 17 anos no ano de 2010, Farias Brito obtém destaque com quase 70\% de concluintes do ensino fundamental na faixa etária considerada e, na outra margem, está Nova Olinda com apenas $47 \%$ de taxa de conclusão.

Como indicador mais generalista do ODM 2, se tem a taxa de conclusão do Ensino Fundamental entre crianças de 15 a 24 anos no ano de 2010 . Na RMC se verificou índices expressivos nesse quesito com proporções superiores aos $93 \%$ de conclusão dessa primeira etapa da educação básica entre jovens de 15 a 24 anos de idade. Os melhores resultados foram, mais uma vez, identificados nos municípios do CRAJUBAR: em Crato (97\%), Barbalha (96,7\%) e Juazeiro do Norte (96,5\%). Nos municípios de Caririaçu (93,5\%) e Missão Velha (93,8\%) se registraram os piores percentuais.

\section{ODM 3 - Promover a Igualdade Entre os Sexos e a Autonomia das Mulheres}

A luta pelos direitos femininos por meio da promoção da igualdade entre os sexos sempre foi discutida em maiores ou menores proporções. Essa prerrogativa também foi contemplada nos ODM, mais precisamente, no terceiro ODM cujo objetivo é promover a igualdade entre os sexos e a autonomia das mulheres e tem por meta eliminar a disparidade entre os sexos nos ensino primário e secundário. Os indicadores para o ODM 3 para a RMC estão expostos na Tabela 03.

De maneira geral, há um predomínio masculino no ensino fundamental dos munícipios da Região Metropolitana do Cariri. A maior desproporção nesse aspecto foi identificada em Farias Brito (100/111) e Crato (100/108). A razão mais proporcional foi verificada em Caririaçu, onde para cada grupo de 100 meninas, existiam 102 meninos. No Ensino Médio, observou-se o inverso do constatado no Fundamental, com prevalência, consideravelmente, feminina nos diversos municípios da RMC. A maior predominância feminina foi observada município de Caririaçu e a menor delas em Crato.

Ressalta-se que o Portal ODM não disponibiliza a razão entre homens e mulheres no ensino superior, hipoteticamente, pela razão da indisponibilidade da matrícula nessa etapa de ensino em alguns municípios. Dessa maneira, esse indicador será analisado somente nos ensinos fundamental e médio.

Tabela 03 - Indicadores relativos ao ODM 3

\begin{tabular}{|c|c|c|c|c|c|c|}
\hline \multirow{2}{*}{ Municípios } & \multicolumn{2}{|c|}{$\begin{array}{l}\text { Razão entre Mulhe- } \\
\text { res e Homens no: }\end{array}$} & \multirow{2}{*}{$\begin{array}{c}\text { Razão entre } \\
\text { mulheres e ho- } \\
\text { mens alfabeti- } \\
\text { zados na faixa } \\
\text { etária de } 15 \text { a } \\
24 \text { anos }\end{array}$} & \multirow{2}{*}{$\begin{array}{c}\text { Proporção } \\
\text { de mulheres } \\
\text { assalariadas } \\
\text { no emprego } \\
\text { formal não } \\
\text { agrícola }\end{array}$} & \multirow{2}{*}{$\begin{array}{c}\text { Percentual de } \\
\text { rendimento femi- } \\
\text { nino em relação } \\
\text { ao masculino no } \\
\text { emprego formal }\end{array}$} & \multirow{2}{*}{$\begin{array}{c}\text { Proporção de } \\
\text { mulheres exer- } \\
\text { cendo mandato } \\
\text { na câmara dos } \\
\text { vereadores (2000 - } \\
\text { 2012) - \% }\end{array}$} \\
\hline & $\begin{array}{c}\text { Ens. } \\
\text { Fundam. }\end{array}$ & $\begin{array}{l}\text { Ensino } \\
\text { Médio }\end{array}$ & & & & \\
\hline Barbalha & $100 / 106$ & $123 / 100$ & $102,7 \%$ & $42,5 \%$ & $95,7 \%$ & $17,6-6,7$ \\
\hline Caririaçu & $100 / 102$ & $171 / 100$ & $107,1 \%$ & $67,4 \%$ & $83,5 \%$ & $20-9,1$ \\
\hline Crato & $100 / 108$ & $102 / 100$ & $102,7 \%$ & $46,0 \%$ & $94,7 \%$ & $0-5,3$ \\
\hline Farias Brito & $100 / 111$ & $127 / 100$ & $104,7 \%$ & $62,3 \%$ & $79,6 \%$ & $15,4-18,2$ \\
\hline Jardim & $100 / 105$ & $134 / 100$ & $103,4 \%$ & $61,6 \%$ & $79,3 \%$ & $13,3-45,5$ \\
\hline Juazeiro do Norte & $100 / 105$ & $124 / 100$ & $102,9 \%$ & $44,0 \%$ & $100,0 \%$ & $4,8-14,3$ \\
\hline Missão Velha & $100 / 105$ & $160 / 100$ & $106,0 \%$ & $50,2 \%$ & $76,2 \%$ & $23,5-15,4$ \\
\hline Nova Olinda & $100 / 105$ & $161 / 100$ & $104,7 \%$ & $44,5 \%$ & $94,4 \%$ & $27,3-22,2$ \\
\hline Santana do Cariri & $100 / 115$ & $140 / 100$ & $106,7 \%$ & $58,1 \%$ & $98,8 \%$ & $18,2-9,1$ \\
\hline
\end{tabular}

Fonte: Elaboração Própria a partir de dados obtidos via Portal ODM 
Sustentabilidade na região metropolitana do Cariri-RMC: análise a partir dos objetivos de desenvolvimento do milênio - ODMs Diego Coelho do Nascimento, Suely Salgueiro Chacon

A razão entre mulheres e homens alfabetizados na faixa etária compreendida entre 15 e 24 anos variou entre 102,7 a 107,1 para um grupo de 100 pessoas do sexo masculino. O que significa que em todos os municípios da Região Metropolitana do Cariri existe maior número de mulheres alfabetizadas do que homens.

A proporção de mulheres assalariadas no emprego formal não agrícola também foi observado no ODM 3. Nesse sentido, na maior parte das cidades que compõem a RMC a participação feminina era maior do que a masculino, exceto nos municípios do CRAJUBAR e Nova Olinda.

Contudo, quando analisado o percentual de rendimento feminino em relação ao masculino no emprego formal, constata-se distorções. No geral, em todos os municípios (exceto, Juazeiro do Norte) os rendimentos femininos para as mesmas funções eram percentualmente inferiores aos masculinos. Juazeiro do Norte foi o único município da Região Metropolitana do Cariri em que os rendimentos masculino e feminino se equivaliam, não havendo acréscimos em razão do sexo. Crato e Barbalha também se aproximam desse quadro de nivelamento entre os rendimentos femininos e masculinos e, por outro lado, Missão Velha apresenta o pior índice, concedendo as mulheres apenas $76,2 \%$ do que ganham os homens.
Outro indicador analisado no alcance do ODM 3 , trata-se da proporção de mulheres eleitas para as câmaras de vereadores municipais. De acordo com o Portal ODM (2012) nas eleições de 2012 o percentual de vereadoras eleitas não ultrapassou os $17 \%$. Para uma melhor análise, optou-se pela comparação entre a proporção de vereadoras eleitas nos pleitos municipais de 2000 e 2012 a fim de se observar aumento ou diminuição da taxa. Nesse sentido, ampliaram o número de vereadoras nas respectivas câmaras municipais, as cidades de Crato, Farias Brito, Jardim e Juazeiro do Norte. Com destaque para o município de Jardim que em 2012 conseguiu aumentar o percentual de vereadoras eleitas para $45,5 \%$. Crato apesar de ter ampliado a participação feminina na câmara de vereadores continua com a pior proporção entre todos os municípios da RMC, com um percentual de mulheres vereadores de apenas $5,3 \%$.

\section{ODM 4 - Reduzir a Mortalidade Infantil}

O quarto ODM é relativo a mortalidade infantil e tem por meta reduzir em dois terços a mortalidade de crianças menores de 5 anos, utilizando-se como indicadores de mensuração a taxa de mortalidade infantil em crianças menores de 5 e 1 ano de idade (Tabela 04).

Tabela 04 - Indicadores relativos ao ODM 4

\begin{tabular}{|c|c|c|}
\hline Município & $\begin{array}{c}\text { Taxa de mortalidade de menores de 5 anos } \\
\text { de idade a cada mil nascidos vivos - } \\
\mathbf{1 9 9 5 - 2 0 1 0}\end{array}$ & $\begin{array}{c}\text { Taxa de mortalidade de crianças } \\
\text { de até um ano de vida a cada mil } \\
\text { nascidos vivos ( 2010) }\end{array}$ \\
\hline Barbalha & 22,3 & 14,4 \\
\hline Caririaçu & 25,9 & 11,7 \\
\hline Crato & 24,8 & 15,7 \\
\hline Farias Brito & 16,6 & 0,0 \\
\hline Jardim & 22,4 & 16,4 \\
\hline Juazeiro do Norte & 16,2 & 11,2 \\
\hline Missão Velha & 22,1 & 11,6 \\
\hline Nova Olinda & 7,6 & 38,3 \\
\hline Santana do Cariri & 31,6 & 3,4 \\
\hline
\end{tabular}

Fonte: Elaboração Própria a partir de dados obtidos via Portal ODM 
No contexto da Região Metropolitana do Cariri ainda é alta a taxa de mortalidade infantil de crianças menores de 5 e de 1 ano de idade. No período de 1995-2010, a maioria dos índices ficou na casa dos $20 \%$. Ressalta-se que o menor índice foi verificado no município de Nova Olinda $(7,6 \%)$ e o maior deles em Santana do Cariri (31,6\%). Os índices de mortalidade em crianças menores de um ano também são altos, sendo a maior taxa de mortalidade a do município de Nova Olinda $(38,3 \%)$ e a menor delas verificada em Farias Brito (0\%).

\section{ODM 5 - Melhorar a Saúde Materna}

O quinto ODM visa melhorar a saúde materna e, para isso, a meta é reduzir em três quartos a taxa de mortalidade materna. São considerados indicadores para a avaliação do cumprimento desse quinto ODM: a taxa de mortalidade materna por 100.000 nascidos vivos; proporção de partos assistidos por profissionais da saúde qualificados, de crianças nascidas sem consultas pré-natais e de crianças nascidas de mães adolescentes. Os dados relativos ao quinto Objetivo de Desenvolvimento do Milênio, encontram-se expostos na Tabela 05.

Os dados obtidos via Portal ODM para o indicador referente a taxa de mortalidade materna por 100.000 nascidos vivos não deixam claro qual a unidade de medida e os procedimentos utilizados para a obtenção do valor exposto. Nesse sentido, as cidades da RMC obtiveram, em sua maioria, índice 0 de mortalidade materna. As únicas exceções foram os municípios de Crato (187,3), Jardim (108,2), Barbalha (97) e Juazeiro do Norte $(24,2)$ que, coincidentemente ou não, abrigam em seus territórios maternidades com grande capacidade de atendimento.

Tabela 05 - Indicadores relativos ao ODM 5

\begin{tabular}{|c|c|c|c|c|}
\hline Município & $\begin{array}{c}\text { Taxa de Morta- } \\
\text { lidade Materna } \\
\text { por 100.000 } \\
\text { nascidos vivos }\end{array}$ & $\begin{array}{c}\text { Proporção de partos assis- } \\
\text { tidos por profissionais da } \\
\text { saúde qualificados }\end{array}$ & $\begin{array}{c}\text { Proporção de crianças } \\
\text { nascidas sem consul- } \\
\text { tas pré-natais }\end{array}$ & $\begin{array}{c}\text { Proporção de } \\
\text { crianças nascidas de } \\
\text { mães adolescentes }\end{array}$ \\
\hline Barbalha & 97 & $99,6 \%$ & $0,6 \%$ & $19,0 \%$ \\
\hline Caririaçu & 0 & $99,5 \%$ & $0,7 \%$ & $19,3 \%$ \\
\hline Crato & 187,3 & $99,7 \%$ & $0,6 \%$ & $19,7 \%$ \\
\hline Farias Brito & 0 & $99,3 \%$ & $0,0 \%$ & $16,6 \%$ \\
\hline Jardim & 108,2 & $99,8 \%$ & $0,8 \%$ & $19,4 \%$ \\
\hline Juazeiro do Norte & 24,2 & $99,8 \%$ & $0,8 \%$ & $19,5 \%$ \\
\hline Missão Velha & 0 & $99,7 \%$ & $0,8 \%$ & $22,2 \%$ \\
\hline Nova Olinda & 0 & $100,0 \%$ & $0,8 \%$ & $28,9 \%$ \\
\hline Santana do Cariri & 0 & $98,4 \%$ & $0,6 \%$ & $22,2 \%$ \\
\hline
\end{tabular}

Fonte: Elaboração Própria a partir de dados obtidos via Portal ODM

A Proporção de partos assistidos por profissionais da saúde qualificados se encaminha para a universalização nos municípios da RM do Cariri, tendo-se em vista que as taxas estão acima dos $99 \%$ (a exceção de Santana do Cariri). A proporção de crianças nascidas sem consultas pré-natais também está se encaminhando para níveis satisfatórios, visto que todas as cidades obtiveram índices inferiores a 1\% de crianças nascidas sem acompanhamento pré-natal.

Mesmo com a constatação de avanços nos indicadores anteriores, ainda é grande o número de crianças nascidas de mães adolescentes com taxas não inferiores aos 16,6\%. A maior taxa de mães adolescentes acontece no município de Nova Olinda $(28,9 \%)$ com e a menor delas em Farias Brito $(16,6 \%)$. 
Sustentabilidade na região metropolitana do Cariri-RMC: análise a partir dos objetivos de desenvolvimento do milênio - ODMs Diego Coelho do Nascimento, Suely Salgueiro Chacon

ODM 6 - Combater o HIVIAIDS, a Malária e Outras Doenças

O combate à disseminação do HIV/AIDS, da malária e outras doenças também se fez presente nos ODMs. O ODM 6 possui duas grandes metas: Ter detido e começado a reverter a propagação do HIV/ AIDS e ter detido e começado a reverter a propagação da malária e de outras doenças. Os indicadores para avaliação do cumprimento do ODM 6 são: Taxa de incidência de HIV/aids (por 100 mil habitantes) por ano; proporção dos casos de HIV/aids entre mulheres; taxas de incidência e mortalidade de doenças transmitidas por mosquito; taxas de incidência e de mortalidade por tuberculose; e taxas de incidência e de mortalidade de hanseníase.

As variáveis expostas na Tabela 06 estão, direta ou indiretamente, relacionadas ao quantitativo populacional dos municípios, tendo-se em vista que, geralmente, quanto maior o número de pessoas em dado município, maior será o número de casos de AIDS e de doenças transmitidas por mosquitos. Prerrogativa confirmada pela análise dos dados da tabela anterior, onde os maiores números de casos de AIDS e de doenças transmitidas por mosquitos foram verificados, respectivamente, nos maiores municípios da RMC: Juazeiro, Crato e Barbalha.

Tabela 06 - Indicadores relativos ao ODM 6

\begin{tabular}{|c|c|c|}
\hline Município & $\begin{array}{c}\text { Número de casos de AIDS registrado por } \\
\text { ano de diagnóstico, segundo gênero } \\
\mathbf{( 1 9 9 0 - 2 0 1 0 )}\end{array}$ & $\begin{array}{c}\text { Número de casos de doenças } \\
\text { transmissíveis por mosquitos } \\
\text { (2001-2010) }\end{array}$ \\
\hline Barbalha & 30 & 2486 \\
\hline Caririaçu & 17 & 298 \\
\hline Crato & 70 & 7398 \\
\hline Farias Brito & 3 & 393 \\
\hline Jardim & 6 & 362 \\
\hline Juazeiro do Norte & 191 & 7710 \\
\hline Missão Velha & 12 & 301 \\
\hline Nova Olinda & 3 & 498 \\
\hline Santana do Cariri & 1 & 362 \\
\hline
\end{tabular}

Fonte: Elaboração Própria a partir de dados obtidos via Portal ODM

Dessa maneira, a tabela 06 comporta dados relacionados ao ODM 6, porém, pela indisponibilidade de informações via Portal ODM, somente se conseguiu a quantidade de casos de AIDS no período de 1990 a 2010 e o número de casos de doenças transmissíveis por mosquitos entre os anos de 2001 a 2010. Sendo assim, as análises relativas ao ODM 6 ficam prejudicadas pela carência de dados específicos para os indicadores elencados para esse ODM.

\section{ODM 7 - Garantir a Sustentabilidade Ambiental}

O último Objetivo de Desenvolvimento do Milênio contempla a dimensão ambiental do desenvolvimento sustentável, destacando a garantia da sustentabilidade ambiental como um desses importantes objetivos a serem implantados em escala mundial. As metas para esse ODM são duas: reduzir pela metade, a proporção da população sem acesso sustentável a água potável e segura; e alcançar melhora significativa nas vidas de habitantes de bairros degradados. Os indicadores de análise do alcance do ODM 7 estão identificados na Tabela 07. 
Tabela 07 - Indicadores relativos ao ODM 7

\begin{tabular}{|c|c|c|c|}
\hline Município & $\begin{array}{c}\text { Proporção de moradores } \\
\text { com acesso a rede geral } \\
\text { de abastecimento de água } \\
\text { canalizada }\end{array}$ & $\begin{array}{c}\text { Proporção de Moradores } \\
\text { com acesso a rede geral de } \\
\text { esgoto ou fossa séptica }\end{array}$ & $\begin{array}{c}\text { Proporção de morado- } \\
\text { res com direito seguro } \\
\text { a propriedade (pró- } \\
\text { pria ou alugada) }\end{array}$ \\
\hline Barbalha & $71,0 \%$ & $17,8 \%$ & $92,2 \%$ \\
\hline Caririaçu & $61,6 \%$ & $16,0 \%$ & $85,7 \%$ \\
\hline Crato & $81,5 \%$ & $42,2 \%$ & $92,8 \%$ \\
\hline Farias Brito & $58,0 \%$ & $12,1 \%$ & $84,9 \%$ \\
\hline Jardim & $38,2 \%$ & $36,5 \%$ & $93,0 \%$ \\
\hline Juaz. do Norte & $90,0 \%$ & $47,2 \%$ & $93,7 \%$ \\
\hline Missão Velha & $60,6 \%$ & $9,7 \%$ & $88,9 \%$ \\
\hline Nova Olinda & $61,0 \%$ & $41,9 \%$ & $88,0 \%$ \\
\hline Sant. do Cariri & $46,6 \%$ & $20,8 \%$ & $86,3 \%$ \\
\hline
\end{tabular}

Fonte: Elaboração Própria a partir de dados obtidos via Portal ODM

Em 2010, a proporção de moradores com acesso a rede geral de abastecimento de água canalizada foi bastante variável nos municípios da Região Metropolitana do Cariri com percentuais variando de $38,2 \%$ a $90 \%$. O acesso a rede de abastecimento de água canalizada é essencial para a melhoria da qualidade de vida da população, entretanto, somente o município de Juazeiro do Norte se aproxima da universalização desse bem com uma proporção de $90 \%$, seguido pelos vizinhos Crato $(81,2 \%)$ e Barbalha (71\%). Na outra margem, encontram-se os munícipios de Jardim e Santana do Cariri com percentuais inferiores aos $50 \%$.

A situação é ainda mais agravante na análise da proporção de moradores com acesso a rede geral de esgoto ou fossa séptica, na qual nenhum dos nove municípios sequer atingiu os $50 \%$. Os que mais se aproximaram foram, respectivamente, Juazeiro do Norte $(47,2 \%)$, Crato $(42,2 \%)$ e Nova Olinda (41,9\%). O munícipio mais distante do alcance dessa meta foi Missão Velha que ser atingiu os $10 \%$ de moradores com acesso a rede de esgoto ou fossa séptica.

Os impactos ambientais verificados no ambiente urbano são diversos, ocorrendo em maior ou menor escala a depender de fatores específicos como grau de urbanização, densidade demográfica, política urbana e ambiental, entre outros. A degradação ambiental é rotina comum nos municípios integrantes da RMC. Os relatórios dinâmicos disponibilizados no Portal ODM identificam e categorizam os impactos ambientais de ocorrência urbana.

A partir da análise do Quadro 01, constata-se a vulnerabilidade ambiental dos munícipios que compõem a Região Metropolitana do Cariri. Em todos eles é comum a ocorrência com frequência de alguma espécie de impacto ambiental urbano. Os recursos hídricos e a preservação da biodiversidade são unanimidade na ocorrência de algum impacto, uma vez que, em todos os municípios da RMC há ocorrências relacionadas a esses dois setores do meio ambiente. 
Sustentabilidade na região metropolitana do Cariri-RMC: análise a partir dos objetivos de desenvolvimento do milênio - ODMs Diego Coelho do Nascimento, Suely Salgueiro Chacon

Quadro 1 - Ocorrência de Impactos ambientais nos Municípios da RMC

\begin{tabular}{|c|c|c|c|c|c|}
\hline \multirow{2}{*}{ Município } & \multicolumn{5}{|c|}{$\begin{array}{l}\text { Ocorrências impactantes observadas frequentemente no meio ambiente nos últimos } 24 \text { meses } \\
\qquad(2008-2010)\end{array}$} \\
\hline & Recurso Hídrico & $\begin{array}{l}\text { Qualida- } \\
\text { de do Ar }\end{array}$ & $\begin{array}{l}\text { Preservação da Biodi- } \\
\text { versidade }\end{array}$ & $\begin{array}{l}\text { Fatores Climá- } \\
\quad \text { ticos }\end{array}$ & Estado do Solo \\
\hline Barbalha & $\begin{array}{l}\text { - Assoreamento de cor- } \\
\text { po d'água }\end{array}$ & - & $\begin{array}{l}\text { - Queimadas } \\
\text {-Desmatamento }\end{array}$ & - & - \\
\hline Caririaçu & $\begin{array}{c}\text { - Assoreamento de cor- } \\
\text { po d'água } \\
\text { - Escassez do } \\
\text { recurso água }\end{array}$ & - & $\begin{array}{c}\text { - Redução do Pescado } \\
\text { - Queimadas } \\
\text {-Desmatamento }\end{array}$ & - & - \\
\hline Crato & $\begin{array}{l}\text { - Assoreamento de cor- } \\
\text { po d'água } \\
\text { - Poluição do recurso } \\
\text { água }\end{array}$ & $\begin{array}{l}\text { - Polui- } \\
\text { ção do ar }\end{array}$ & $\begin{array}{c}\text { - Queimadas } \\
\text {-Desmatamento } \\
\text { - Degradação de áreas } \\
\text { protegidas }\end{array}$ & - & $\begin{array}{l}\text { - Contaminação } \\
\text { do solo }\end{array}$ \\
\hline $\begin{array}{c}\text { Farias } \\
\text { Brito }\end{array}$ & $\begin{array}{c}\text { - Assoreamento de cor- } \\
\text { po d'água } \\
\text { - Escassez do } \\
\text { recurso água } \\
\text { - Poluição da água }\end{array}$ & - & $\begin{array}{l}\text { - Redução do } \\
\text { Pescado } \\
\text { - Queimadas } \\
\text {-Desmatamento }\end{array}$ & $\begin{array}{l}\text { - Atividade agrí- } \\
\text { cola prejudicada }\end{array}$ & - \\
\hline Jardim & $\begin{array}{l}\text { - Escassez do } \\
\text { recurso água }\end{array}$ & - & $\begin{array}{c}\text {-Desmatamento } \\
\text {-Degradação de áreas } \\
\text { protegidas }\end{array}$ & - & - \\
\hline $\begin{array}{l}\text { Juazeiro } \\
\text { do Norte }\end{array}$ & $\begin{array}{l}\text { - Assoreamento de cor- } \\
\text { po d'água } \\
\text { - Poluição do recurso } \\
\text { água }\end{array}$ & $\begin{array}{l}\text { - Polui- } \\
\text { ção do ar }\end{array}$ & $\begin{array}{c}\text { - Queimadas } \\
\text {-Desmatamento } \\
\text { - Degradação de áreas } \\
\text { protegidas }\end{array}$ & $\begin{array}{c}\text { - Atividade agrí- } \\
\text { cola } \\
\text { Prejudicada }\end{array}$ & $\begin{array}{c}\text { - Contaminação } \\
\text { do solo }\end{array}$ \\
\hline $\begin{array}{l}\text { Missão } \\
\text { Velha }\end{array}$ & $\begin{array}{c}\text { - Assoreamento de cor- } \\
\text { po d'água } \\
\text { - Escassez do } \\
\text { recurso água } \\
\text { - Poluição da água }\end{array}$ & - & $\begin{array}{c}\text {-Queimadas } \\
\text {-Desmatamento }\end{array}$ & $\begin{array}{c}\text { - Atividade pecu- } \\
\text { ária } \\
\text { prejudicada } \\
\text { - Atividade agrícola } \\
\text { Prejudicada }\end{array}$ & $\begin{array}{c}\text { - Contaminação } \\
\text { do solo }\end{array}$ \\
\hline $\begin{array}{l}\text { Nova } \\
\text { Olinda }\end{array}$ & $\begin{array}{c}\text { - Assoreamento de cor- } \\
\text { po d'água } \\
\text { - Escassez do } \\
\text { recurso água } \\
\text { - Poluição da água }\end{array}$ & $\begin{array}{l}\text { Poluição } \\
\text { do ar }\end{array}$ & $\begin{array}{c}\text {-Queimadas } \\
\text {-Desmatamento }\end{array}$ & $\begin{array}{c}\text { - Atividade agrí- } \\
\text { cola } \\
\text { Prejudicada }\end{array}$ & - \\
\hline $\begin{array}{c}\text { Santana } \\
\text { do Cariri }\end{array}$ & $\begin{array}{l}\text { - Escassez do } \\
\text { recurso água }\end{array}$ & - & $\begin{array}{c}\text { - Queimadas } \\
\text {-Desmatamento }\end{array}$ & - & $\begin{array}{c}\text { - Contaminação } \\
\text { do solo }\end{array}$ \\
\hline
\end{tabular}

Fonte: Elaboração Própria a partir de dados obtidos via Portal ODM 
Juazeiro do Norte apresenta o pior contexto ambiental no comparativo com outros municípios da $\mathrm{RMC}$, existem ocorrência de impactos ambientais em todas as categorias analisadas. Premissa que pode ser justificada pela grande taxa de urbanização desse município e pela carência de estratégias de desenvolvimento urbano sustentável a nível municipal.

Sendo assim, a Região metropolitana do Cariri tem como principal desafio a garantia a preservação ambiental que, conforme visto, apresenta situação difícil - mas não impossível - de resolução.

Desperta atenção o fato de que os municípios do CRAJUBAR apresentam o pior contexto no âmbito metropolitano, possibilitando uma reflexão sobre a política desenvolvimentista adotada pelos mesmos, pautada e mantida no crescimento econômico na crença que a partir desse o desenvolvimento se concretizará.

\section{Região Metropolitana do Cariri: Um Panorama de Insustentabilidade}

Apesar de específicos, a mensuração dos ODMs na Região Metropolitana do Cariri confirmou o que já é bem evidente em outras regiões metropolitanas: diferenças intrarregionais. É bem notório que a RMC possui dois contextos diferentes: De um lado, o CRAJUBAR; Do outro, os municípios que o circundam. No primeiro grupo a condição socioeconômica é melhor, mas com um sério prejuízo ambiental. Já no segundo grupo, até pela menor pressão demográfica, temos o inverso desse processo, ou seja, temos uma condição ambiental regular (mas já preocupante) e um contexto socioeconômico desfavorável.

Em termos amplos, uma tônica no processo de metropolização brasileiro é o crescimento da periferia urbana nos grandes centros urbanos e áreas adjacentes. O processo de urbanização e metropolização por meio da:

[...] expansão da malha urbana empurra o pobre para espaços cada vez mais distantes do núcleo metropolitano, onde se encontra a oferta de emprego ou para a ocupação irregular de terra e favelização, ao mesmo tempo em que assegura a constituição de reservas de valor na orma de capital imobiliário (CANO; BRANDÃO, 2002, p. 443).
Na RMC está realidade está em curso, nos municípios do CRAJUBAR se observa uma valorização imobiliária em curva crescente nas áreas mais acessíveis no que concerne à mobilidade urbana ou mais propícias à ocupação (terrenos planos dotados de infraestrutura ou com amenidades ambientais). Tudo isso faz com que a população com menor renda tenha que estabelecer moradia em bairros muito distantes das regiões centrais das cidades ou até mesmo trabalhar e morar em locais diferentes para economizar renda. Resumidamente, essa diferença intrarregional pode levar a um fluxo migratório para os municípios do CRAJUBAR (em sua maioria, para áreas distantes da centralidade urbana ou favelas) ou a transformação das cidades do entorno em cidades dormitórios. Uma vez que, os municípios do entorno do núcleo metropolitano possuem menor capacidade financeira, ofertando menores possibilidades de emprego e renda para a população residente e caracterizando-se por altas demandas por habitação, saúde, educação, transporte público e outras necessidades citadinas (SZUCHMAN; HARDT; OBA, 2006).

Ainda conforme exposto pela análise dos ODMs, são muitas as problemáticas nos municípios que integram a Região Metropolitana do Cariri, entretanto, a partir delas podem ser vislumbradas potencialidades. Laczynski (2010, p. 10) coloca como potencial e prioridade das regiões metropolitanas os seguintes aspectos: planejamento integrado do desenvolvimento econômico e social; saneamento básico; uso do solo metropolitano; transporte e sistema viário; produção e distribuição de gás combustível canalizado; aproveitamento dos recursos hídricos e controle da poluição ambiental; e outros serviços definidos por lei federal.

Em complemento, Grostein (2001, p. 14) afirma que a sustentabilidade no âmbito metropolitano deve estar baseada em um conjunto de variáveis físico-urbanísticas, como:

[...] a forma de ocupar o território; a disponibilidade de insumos para seu funcionamento (disponibilidade de água); a descarga de resíduos (destino e tratamento de esgoto e lixo); o grau de mobilidade da população no espaço urbano (qualidade do transporte público de massa); a oferta e o atendimento 
às necessidades da população por moradia, equipamentos sociais e serviços; e a qualidade dos espaços públicos.

Dessa forma, a Região Metropolitana do Cariri está longe do ideal de sustentabilidade em suas dimensões social, econômica e ambiental (esta última com mais ênfase ainda). Porém, algumas alternativas e caminhos a serem trilhados já foram expostos, carecendo para tanto de planejamento e implementação.

\section{CONSIDERAÇÕES GERAIS}

O cenário exposto a partir do detalhamento do caso da Região Metropolitana do Cariri expõe as fragilidades da mesma e o longo caminho a ser trilhado na busca pela sustentabilidade.

Ainda são persistentes as diferenças sócioeconômicas no seu conjunto de municípios, conforme os dados analisados dos Objetivos de Desenvolvimento do Milênio - ODM. Uma ressalva precisa ser considerada nesse sentido, os municípios do CRAJUBAR encontram-se em condição sócioeconômica privilegiada e ambientalmente desfavorável. Gerando um panorama insustentável a médio e longo prazo com repercussões até mesmo sobre as gerações atuais.

É pertinente a existência de uma política de planejamento estratégico regional que delimite as formas de gerir, organizar e as prioridades que devem ser consideradas para a melhoria da condição sócioeconômica e ambiental de cada um dos municípios da RMC. No planejamento da Região Metropolitana do Cariri é preciso incorporar políticas públicas que convirjam para a sustentabilidade visando ter como resultado a transformação do meio social, econômico e ambiental.

\section{REFERÊNCIAS BIBLIOGRÁFICAS}

BRAGA, T. M.; et al. Índices de sustentabilidade municipal: o desafio de mensurar. Belo Horizonte: UFMG/Cedeplar, 2003. 22p. (Texto para discussão; 225).

CANO, W.; BRANDÃO, C. A. A Região Metropolitana de Campinas: Urbanização, economia, finanças e meio ambiente. Campinas: Ed. da UNICAMP, 2002.
CHACON, S. S. O sertanejo e o caminho das águas: políticas públicas, modernidade e sustentabilidade no semi-árido. Fortaleza: Banco do Nordeste do Brasil, 2007. 354 p. (Série BNB teses e dissertações, n. 08). GIL, A. C.; Como Elaborar Projetos de Pesquisa. 5. Ed. São Paulo: Atlas, 2010.

GROSTEIN, M. D. Metrópole e Expansão Urbana: A Persistência de Processos "Insustentáveis". São Paulo em Perspectiva, 15(1) 2001. Disponível em: < http://www.scielo.br/scielo.php?script=sci arttext\&pid $=$ S0102-88392001000100003\& $\operatorname{lng}=\mathrm{pt} \& \mathrm{nrm}=\mathrm{iso} \& \mathrm{t} \operatorname{lng}=\mathrm{pt}>$. Acesso em: $30 \mathrm{abr}$. de 2012. DOI: http://dx.doi.org/10.1590/S010288392001000100003

GUIA PARA A MUNICIPALIZAÇÃO DOS OBJETIVOS DO MILÊNIO. Referências para a adaptação de indicadores e metas à realidade local. Agenda Pública - Agência de Análise e Cooperação em Políticas Públicas (elaboração), São Paulo: [s.n.], 2009.

INSTITUTO BRASILEIRO DE GEOGRAFIA E ESTATÍSTICA - IBGE. Censo Demográfico 2010. Disponível em: < http://www.ibge.gov.br>. Acesso em: 22 mar. de 2012.

PORTAL ODM. Acompanhamento brasileiro dos Objetivos de Desenvolvimento do Milênio. Disponível em: $<$ http://www.portalodm.com.br/ >. Acesso em 10 de Setembro de 2012.

SEVERINO, A. J. Metodologia do Trabalho Cientifico. 23 ed. rev. e atual. São Paulo: Cortez, 2007.

SZUCHMAN, T.; HARDT, C.; OBA, L. Gestão de Municipios de Áreas Metropolitanas. IN: III ENCONTRO DA ANPPAS, 23 a 26 de maio de 2006, Brasília-DF.

YIN, R. K.; Estudo de Caso: planejamento e métodos. 3. ed. Porto Alegre: Bookman, 2005. 1. Ed. 1985.

WORLD COMMISSION ON ENVIRONMENT AND DEVELOPMENT - WCED. Our Common Future. Brundtland Report, Berna: WCED, 1987. 